\title{
Transnational Social Workers: Making the Profession a Transnational Professional Space
}

\author{
Allen Bartley, Liz Beddoe, Christa Fouché, and Phil Harington \\ School of Counselling, Human Services and Social Work, Faculty of Education, University of Auckland, \\ Private Bag 92601, Symonds Street, Auckland 1150, New Zealand \\ Correspondence should be addressed to Allen Bartley, a.bartley@auckland.ac.nz
}

Received 3 February 2012; Accepted 26 April 2012

Academic Editor: Shirlena Huang

Copyright ( 2012 Allen Bartley et al. This is an open access article distributed under the Creative Commons Attribution License, which permits unrestricted use, distribution, and reproduction in any medium, provided the original work is properly cited.

This paper draws on research conducted in New Zealand from 2009 to 2011 with overseas-qualified social workers as members of a global profession experiencing both great international demand for their skills and unparalleled flows of professional transnationalism. In line with the international social work literature, this cohort of migrant professionals offers a range of needed skill and expertise as well as unique challenges to local employers, client communities, and the social work profession as a whole. With a specific focus on mixed-methods data dealing with participants' induction experiences and engagement with professional bodies, this paper argues that migrant social workers have created in New Zealand a transnational professional space that demands a response from local social work stakeholders.

\section{Introduction}

Through the 1990s, the migration studies literature began to address what was then interpreted to be an emerging phenomenon of transnational migration, in which "migrants establish social fields that cross geographic, cultural and political borders" [1, p.ix]. The early work in the field, championed by Schiller, Portes, and their respective collaborators focused primarily on the movement of people from the less developed countries to "centres of capital" (ibid., p.x). Since that time the field has expanded dramatically, as scholars documented the transnational practices of "South-North" flows, as highlighted above, and "South-South" flows (as in studies of the flows of domestic and construction workers across Asia), as well as movements of educated professionals across multiple markets. Flexible regimes of immigration and incorporation [2], and an increasingly open and flexible global financial system, have allowed growing numbers of highly educated professionals and business entrepreneurs to pursue and maintain professional and personal ties across national borders in a variety of family arrangementsincluding multilocal families [3], either via the "astronaut" strategy of the main breadwinner returning to the origin society or with members of the 1.5 or second generation leaving the destination society to return or on-migrate in search of career or further educational opportunities, leaving parents and other siblings behind [4].

The argument put forward by in this literature is that, as transnational migrants engage in such patterns of intense contact and exchange between both sending and receiving societies (and perhaps others as well), the engaged social fields merge and create opportunities to pursue alternatives to the conventional path of settlement and "gradual but inevitable assimilation" [5, page 228].

Whereas, previously, economic success and social status depended exclusively on rapid acculturation and entrance into mainstream circles of the host society, at present they depend (at least for some) on cultivating strong social networks across national borders. For immigrants involved in transnational activities and their home country counterparts, success does not so much depend on abandoning their culture and language to embrace those of another society as on preserving their original cultural endowment, while adapting instrumentally to a second (ibid., p.229). 
The description applies not only to transnational professionals themselves, but to their "professional culture" as well. In addition to adjusting to the demands of professional practice in a new local context, transnational practitioners, such as the social workers in the study addressed in this paper, often maintain a working knowledge of developments in their profession in the countries from which they have emigrated, and other jurisdictions as well. It is this "simultaneous embeddedness" [7, page 48], which characterises transnational migrants, and while their migration practices are characteristic of the "boundary-breaking process in which two (usually) or more nation-states are penetrated by and become part of a singular new social space" [8, page 565], we suggest that their embeddedness in their profession across borders creates a single professional social space, characterised by sustained, high-density, cross-border ties of persons, networks, and organisations ([9]: 2).

In this paper, we present, as a case study of such a transnational social space, results of research conducted in New Zealand with transnational social workers-that is, social work practitioners working in New Zealand who gained their social work qualifications in other countries. In describing their experiences, particularly with regard to their induction into New Zealand social work practice and their engagement with the professional bodies in New Zealand, we argue that the transnationalism of this cohort of professionals continues to challenge governments, health and social service employers, and indeed the profession itself, to develop adequate means to understand and engage with transnational social work as a complex transnational professional space.

\section{New Zealand as a Particular Site for Studying Transnationalism}

As an immigrant receiving country, the cultural diversity of New Zealand's population has increased dramatically since policy changes in the late 1980s refocused immigration policy to favour applicants with high levels of human capital-advanced qualifications, professional or entrepreneurial experience-and/or economic wealth. Since that time, highly qualified professionals from East and South Asia (Taiwan, Korea, Japan, Hong Kong and India, and, since the mid-1990s, China), South Africa, and Eastern Europe have joined the ranks of newcomers with those from New Zealand's traditional sources, the UK, Ireland and Australia, and the Pacific Island nations (Table 1). Taken together, the number of residency approvals for "Asians" has supplanted approvals for Europeans every year since 1987-a fact unimaginable (and impossible) before the policy shift. At the last Census, nearly a quarter of the country's population were foreign-born; (The last New Zealand Census was conducted in 2006. The 2011 Census was postponed until 2013, due to the disruption caused by the series of earthquakes that have devastated Christchurch, New Zealand's second-largest city, since September 2010.) this diversity is even more dramatic in Auckland (New Zealand's largest—and arguably only international—city), where 40 percent of residents were born
TABLE 1: Birthplace of New Zealand's resident population.

\begin{tabular}{lcc}
\hline & $N$ & $\%$ \\
\hline New Zealand & $2,960,214$ & 73.5 \\
UK and Ireland & 251,688 & 6.2 \\
Asia & 251,130 & 6.2 \\
Pacific Islands & 135,852 & 3.4 \\
Europe (excl UK and Ireland) & 68,067 & 1.7 \\
Australia & 62,742 & 1.6 \\
North America & 26,940 & 0.7 \\
Other & 271,311 & 6.7 \\
\hline Total & $4,027,947$ & 100.0 \\
\hline
\end{tabular}

Source: [6].

overseas, the largest number of these coming from China (Statistics New Zealand, n.d.).

The transnational features of those "new settler" communities have been canvassed elsewhere [3, 10-13]. However, the well-documented difficulties for many "Asian" migrants in gaining commensurate or satisfactory employment opportunities, the frequent short-term departures (as well as long-term returns) to their countries of origin, the high levels of on-migration to other countries (most notably Australia), and the prevalence of "multi-local" or "astronaut" families [3] all characterise a common experience among New Zealand's migrant population. Further, these strategies mirror the long-stranding New Zealand tradition of the "OE"- the overseas experience, which is the practice engaged in by generations of young New Zealanders of travelling abroad to gain overseas work or educational (and leisure) experience $[10,13]$. It is the convergence of these factors - the small national population impacted by new and dramatic cultural, ethnic and linguistic diversity, the high levels of transnational activity, and the fact that the threshold for full economic and political integration in New Zealand society is permanent residence, rather than citizenship-that all combine to make New Zealand an ideal site for exploring the impact of transnational migration strategies and their impact on specific professions.

\section{Social Work as a Global Profession}

Social work is a global profession practised in over 140 countries. Its spread and development have been accompanied by a drive to attain professional status and a coherent international identity through the work of a number of international organisations concerned with social work practice and education, such as the International Federation of Social Workers (IFSW) and the International Association of Schools of Social Work (IASSW). An obvious manifestation of this is the continuing drive to develop a single global definition of what social work actually is [14-16]. The global nature of the profession is reflected in the large number of international professional and academic social work publications and, in Europe, the imperatives of various EU directives and initiatives like the Bologna Declaration have motivated social work educators and registering authorities 
to move towards a closer alignment of practice standards to a European norm [17].

Additionally, efforts have increased by agencies and organisations in many countries to recruit international social workers to fill local shortages. Often these efforts are juxtaposed by changes in official immigration policies to facilitate the transnational movement of social workers and other professionals. Similar to countries such as England, Canada, and Australia, New Zealand has been actively recruiting social workers from abroad to fill a critical labour shortage that cannot be met internally, and social work is currently listed on the New Zealand government's Long-Term Skills Shortage List. This allows migrants with a social work qualification and professional experience to apply for either a work-to-residence or residency permit in New Zealand [18]. Migrants with a degree equivalent to a New Zealand Bachelor of Social Work or a Graduate Diploma in Social Work (as assessed by the New Zealand Qualifications Authority) are able to claim points as a social work professional on their migration applications. The literature from the UK suggests that social work agencies aggressively recruit and market to migrants the benefits of moving there, in the hopes that this labour pool will fill gaps in its social care system [1924]. There are signs that this aggressive campaign has had success. In the UK, between 2003 and 2004 there was an 82 percent increase in the number of overseas-qualified social workers entering the country, with the greatest numbers coming from Australia, South Africa, and the USA [23]. In this transnational dynamic, New Zealand is both a receiving and sending country, as the local labour shortage is further exacerbated by New Zealand-trained social workers departing for positions overseas.

As social workers globally apprehend these various signals from governments and agencies, a range of transnational opportunities are open for them: to seek greater professional and economic opportunities, to travel and gain novel cultural experiences, and to settle in more "attractive" countries (however one may define this) [25]. However, despite the globalising characteristics of the profession, and the fact that qualified social workers may be ranked among the "highly skilled" and sought-after, border-crossing social workers can hardly be conceptualised as members of the Transnational Capitalist Class [26], or indeed as sharing a similar economic or professional location as other "highly skilled professionals" often associated with the activities of transnational corporations or capitalist elites [27, 28]. Rather, because of its role as a "helping" profession, its largely female workforce [29] and the relationship between the profession and state-controlled systems of delivery, social work as a profession is far more akin to nursing or teaching than other highly skilled professions more closely linked to global capital. As such, migrant social workers may considered to be among the "middling transnationals" [30].

In a global environment where immigration policies are more welcoming to such professionals, social workers may imagine that theirs is easily accommodated as a transnational profession. Globalisation and labour mobility have led some to argue that there is a central set of values and ethics particular to social work, that transcends national boundaries [23]. Most countries, including New Zealand, now have a set of ethical standards, some of which has been informed by the International Federation of Social Work's (IFSW) Code of Ethics, but others of which are informed by the values and priorities specific to the practice of social work in a specific context [31]. Similarly, higher educational programmes in social work across a number of countries, including New Zealand, now stress "universal social work professional values" such as self-determination, confidentiality, being nonjudgmental, and acceptance and respect for diversity $[23,32]$.

However, these values and ethical codes are always interpreted through the lens of national or regionally specific historical, social, political, and cultural norms [21,23]. These norms are manifest in a range of challenges that confront transnational social workers: in employment practices and workplace cultures; in negotiating new sets of legislative imperatives and political tensions; in gaining recognition and acceptance of the validity and transportability of their educational qualifications, skills, and practice expertise gained overseas. The challenges confront the profession as a whole as well: in New Zealand, there is a tension between the "push" for education to become more indigenous, to better serve local practice, and the "pull" to prepare graduates for the growing international labour market for social workers, so that they may take advantage of transnational opportunities in other jurisdictions [33].

While we acknowledge that migrant social workers in New Zealand are a highly diverse group of professionals, our aim in this paper is not focused on mapping the differences in their experiences as they encounter their communities of practice in a new destination. Rather, for the purposes of this discussion, we wish to highlight the fact thatwherever they have lived or been educated, in whichever jurisdictions or fields of social work they have practiced, whatever their motives for migration - their simultaneous membership in a global profession and their transitions to unfamiliar communities of practice constitute these migrant professionals as a particular case through which to explore the development of social work as a transnational professional space.

\section{Methodology}

The research reported in this paper is from the "Migrant Professionals" project based at the University of Auckland and utilised a combination of qualitative and quantitative strategies. Ethics approval was obtained from the University of Auckland Human Participants Ethics Committee for a project undertaken in three stages. The first stage comprised an examination of the key characteristics of the 234 registered social workers in New Zealand with an overseas social work qualification, the results of which have been reported elsewhere [34]. The two later stages were designed together as a sequential mixed-methods design: key informant group interviews with 18 migrant social work practitioners (Stage 2 of the study) informed the third stage, comprising a survey of 294 overseas-qualified social workers in New Zealand. 
The group interview participants were recruited via snowball and purposive sampling from professional networks. The interview schedule for the four group interviews was built from issues identified in a review of the international literature dealing with migrant social workers, and the results were mined both to give clarity and scope to the design of the survey questions and to provide a rich data source in their own right, via qualitative thematic analysis.

The survey was administered online; the weblink was publicised via an e-mail to the membership of the Aotearoa New Zealand Association of Social Workers (ANZASW) with a request to forward to members' personal and professional networks. An advertisement was also included in the newsletter of the New Zealand Federation of Voluntary Welfare Organisations (NZFVWO) as an attempt to reach social work qualified individuals not registered with the professional body and potentially working in the voluntary sector. Survey results were subjected primarily to descriptive statistical analysis (i.e., frequency distributions, bivariate and multivariate analysis); the large number of categories in most of the variables and the number of responses received made more sophisticated statistical analysis unfruitful. However, alongside an array of closed-response questions, the survey also contained a substantial number of open-response questions, which were analysed in a similar qualitative vein as the group interview data. Thus, the study may be considered to have utilised a qualitatively focused, multistrand sequential mixed-methods design $[35,36]$. The findings reported in this paper are drawn from analysis of all three phases of the research.

Research amongst this professional population is challenging in New Zealand. The social work profession in New Zealand does not enjoy protected title, nor is the registration of social workers mandatory, so it is impossible to gain a definitive picture of how many social workers are actually employed in New Zealand-whether or not the work they do has "social worker" in the title. Additionally, social work qualified professionals not currently practicing as social workers are far less likely to have access to the range of professional publications and network resources through which research recruitment is undertaken. In short, this is a population whose numbers in New Zealand are not precisely known. While the Social Workers Registration Board (SWRB) holds a great deal of information about those who have submitted to the process of professional registration, both the cost and the various professional demands placed on them as conditions of on-going registration (i.e., regular professional supervision and periodic assessments of competency) mean that these are also the professionals most likely to have achieved - and maintained-stable employment as social workers since their arrival in New Zealand.

\section{Results}

Of the 294 social workers who completed the online survey, 236 were female and 54 male. The age of this sample mostly ranged between 40 and 59 (60.6\%), while $31.3 \%$ reported to be $20-39$ years old, with $7.1 \%$ aged 60 and over. Nearly three-quarters $(71.4 \%)$ of the participants had been in New Zealand less than 10 years with $8.3 \%$ reporting to be in New Zealand more than 20 years. The majority of participants possessed high levels of skills and qualifications prior to coming to New Zealand; most participants held a social work qualification degree at Bachelor or Masters level, although thirty held postqualifying masters and six held doctorates. Almost 30\% ( $N=87)$ were currently employed by a District Health Board (DHB); 24\% $(N=71)$ worked for the Department of Child, Youth and Family (the statutory child welfare agency-CYF); $11.9 \%$ in NGO child and family services; $6.5 \%$ in NGO mental health services and the remainder across a wide range of jobs in NGO community services, tertiary education, and self-employment.

5.1. Diversity of New Zealand Social Work Workforce. As stated above, it is impossible to know how many migrants in New Zealand possess overseas social work qualifications. However, as of August 2010 there were 234 overseas-qualified registered social workers practicing in New Zealand, from 32 different countries, comprising over 9 percent of the total number of New Zealand-registered social workers (Table 2). Though likely only a subset of the numbers of the migrant social workers working in New Zealand [34], this figure closely corresponds to the proportion of overseas-qualified social workers registered in the UK [25] and in the Republic of Ireland [17]. Fully a third of the New Zealand-based professionals were born in the UK or Ireland, with a further $18 \%$ from the rest of Europe-mostly from Germany and the Netherlands. There is also a notable proportion (14.5\%) of South Africans. The New Zealand registration data include 23 New Zealand-born transnationals who gained their social work qualifications overseas and have since returned. Respondents in the "Migrant Professionals" survey were from a similarly wide range of countries, with many demonstrating a transnational disposition before migrating to New Zealand: more than a third of respondents received their professional social work qualification in a country other than their country of birth.

5.2. Motives for Migration. Far from being detached free agents in a global marketplace, transnationals are often "grounded" in the everyday, such as the demands of family relationships and the educational needs of children [37]. This is certainly manifest in the lives of the social workers in our study. Of the survey participants who answered the question about their motives for moving to New Zealand, just under a quarter identified employment-related factors as their primary reason for migration (Table 3 ). Only one in ten respondents was actually recruited from overseas into a position. More than half the respondents identified a range of family and other relationship-related motives, including accompanying a family member, reuniting with kin who had previously migrated, and even "fell in love with a Kiwi!" ("Kiwi" is a colloquial expression variously used to refer to all native-born New Zealanders, New Zealand citizens, oras an ethnic signifier-to members of the dominant ethnic group, New Zealanders of Western European backgrounds.) Motives coded as "Other" included a range of responses regarding lifestyle and environmental factors, the adventure 
TABLE 2: Birthplaces of overseas-qualified social workers registered in New Zealand.

\begin{tabular}{|c|c|c|c|c|c|}
\hline Country & $N$ & $\%$ & Region & $N$ & $\%$ \\
\hline England & 63 & 26.9 & \multirow{5}{*}{ UK \& Ireland } & \multirow{5}{*}{78} & \multirow{5}{*}{33.3} \\
\hline Scotland & 7 & 3 & & & \\
\hline Wales & 4 & 1.7 & & & \\
\hline Ireland & 2 & 0.9 & & & \\
\hline Northern Ireland & 2 & 0.9 & & & \\
\hline Austria & 1 & 0.4 & \multirow{12}{*}{ Europe } & \multirow{12}{*}{41} & \multirow{12}{*}{17.5} \\
\hline Belgium & 1 & 0.4 & & & \\
\hline Bulgaria & 1 & 0.4 & & & \\
\hline Czech Republic & 1 & 0.4 & & & \\
\hline France & 2 & 0.9 & & & \\
\hline Germany & 16 & 6.8 & & & \\
\hline Italy & 1 & 0.4 & & & \\
\hline Malta & 1 & 0.4 & & & \\
\hline Netherlands & 13 & 5.6 & & & \\
\hline Romania & 2 & 0.9 & & & \\
\hline Switzerland & 1 & 0.4 & & & \\
\hline Yugoslavia & 1 & 0.4 & & & \\
\hline South Africa & 34 & 14.5 & \multirow{2}{*}{ Africa } & \multirow{2}{*}{35} & \multirow{2}{*}{15} \\
\hline Zambia & 1 & 0.4 & & & \\
\hline Australia & 8 & 3.4 & \multirow{3}{*}{ Oceania } & \multirow{3}{*}{32} & \multirow{3}{*}{13.7} \\
\hline Fiji & 1 & 0.4 & & & \\
\hline $\mathrm{NZ}$ & 23 & 9.8 & & & \\
\hline India & 17 & 7.3 & \multirow{2}{*}{ South Asia } & \multirow{2}{*}{19} & \multirow{2}{*}{8.1} \\
\hline Bangladesh & 2 & 0.9 & & & \\
\hline Canada & 8 & 3.4 & \multirow{2}{*}{ North America } & \multirow{2}{*}{18} & \multirow{2}{*}{7.7} \\
\hline USA & 10 & 4.3 & & & \\
\hline Hong Kong & 2 & 0.9 & \multirow{4}{*}{ East Asia } & \multirow{4}{*}{9} & \multirow{4}{*}{3.8} \\
\hline Korea & 1 & 0.4 & & & \\
\hline Philippines & 5 & 2.1 & & & \\
\hline Singapore & 1 & 0.4 & & & \\
\hline Lebanon & 1 & 0.4 & \multirow{2}{*}{ West Asia/Middle East } & \multirow{2}{*}{2} & \multirow{2}{*}{0.9} \\
\hline Monaco & 1 & 0.4 & & & \\
\hline Total & 234 & 100 & Total & 234 & 100 \\
\hline
\end{tabular}

Source: SWRB.

TABle 3: Primary motive for migration $(n=290)$.

\begin{tabular}{lcc}
\hline & $N$ & $\%$ \\
\hline Family/relationship related & 151 & 52.1 \\
Other reason & 70 & 24.1 \\
Profession/work related & 69 & 23.8 \\
\hline Total & 290 & 100.0 \\
\hline
\end{tabular}

of an overseas experience, and the prospect of greater safety/security.

On the one hand, these responses seem to contradict the generally accepted profile of the highly educated globalised knowledge worker, entrepreneur, or medical professional, seeking advantageous opportunities as "global careerists" $[30,38,39]$. However, as stated earlier, social work is a female-dominated profession; given the predominant model of family migration in two-parent families-even when both partners are employed professionals before migration-a gendered division of labour often occurs where one partner (usually female) shifts focus away from commensurate employment in the new country towards facilitating the adjustment and settlement of the family [40]. In those cases, having become an "accompanying family member" to the primary migration applicant, a female professional may have some period out of the labour force, only reentering when the family is more settled or her personal circumstances change. On the other hand, motivations for migration are almost always complex, and the mix of career, family and other considerations driving migrant decisionmaking need not be mutually exclusive. Several of the participants of the key informant group interviews in this study certainly fit the "global careerist" trajectory, while other participants related their experiences as the initial "homemaker." The appearance of both these archetypes amongst the group interview participants_all of whom had achieved senior practitioner roles in New Zealand-suggests that the impact of migrant motivations on the careers of these social workers is worthy of further research. Given the nature of New Zealand's immigration policy, focused as it is on labour market participation, those social workers who came to New Zealand as primary applicants without a job offer in handor who were unable to acquire one within a relatively short timeframe-would likely not have been allowed to remain. Thus it is reasonable to assume that those participants whose primary motive for migrating was relationship based were accompanying bread-winning partners.

\subsection{Experiences of Employment/Impact on Professional Iden-} tity. Survey participants were asked a range of employmentrelated questions, including their job satisfaction, work histories, and experiences with discrimination and mistreatment. These results have been-and will be-reported elsewhere. As most of the participants were from countries in which social work practice shares many essential characteristics with New Zealand, it is not surprising to note that just over half of the survey participants who had been recruited from overseas into social work positions in New Zealand came from the UK or Ireland; a further 21\% were from the USA or Canada. These figures align with research confirming that social work/social care employers in the UK generally prefer workers with practice experience either in the UK or from countries presumed to have a similar social care/work ethos and practice [41].

However, two areas in which participants in the current study encountered very significant issues were the provision and quality of induction into the New Zealand social work context, and the extent to which their practice of social work in New Zealand allowed them to make good use of their range of professional training and skills. The significance of these two areas of enquiry indicate much about the transnational nature of the social work profession in New Zealand. As stated earlier, New Zealand relies on overseas-qualified and experienced social workers to fill critical labour market shortages despite the centrality of 
local knowledge to effective practice. Such local knowledge is focused particularly in the areas of local legislation, social policy, and regulation and in dealing effectively with New Zealand's indigenous population who occupy a unique place in New Zealand society as both partner with the Crown to the Treaty of Waitangi, and a significant client community in receipt of statutory services. Given the legal and political role of the Treaty and the profession's ethical commitment to recognising the "special status" of Maori cultural practices and imperatives, practitioners new to the New Zealand context must be given access to knowledge and skills in these key areas before they can begin to practice competently and ethically in New Zealand.

At the same time, transnational social workers come with a range of qualifications and practice competencies and experience that may not only contribute to the local professional context, but indeed expand it as intervention models and skill sets developed overseas are able to be put into practice in new settings. Thus a cross-pollination may occur which can bring benefits to both the profession and client communities.

\section{Induction}

In New Zealand social work, induction of migrant professionals is offered solely in the context of employment. Neither the Social Workers Registration Board (SWRB), nor the professional association, the Aotearoa New Zealand Association of Social Workers (ANZASW) offer systematic or comprehensive induction training for overseas-qualified social workers hoping to practice in New Zealand. Of the 226 survey participants who had been employed as social workers in New Zealand, just fewer than half (47\%) indicated that they had received any induction in New Zealand social work practice at their first New Zealand social work posting (Table 4). These figures varied according to the type of employment environment: fewer than 3 in 10 respondents working in nonstatutory settings (including NGOs, community organisations, or tertiary education) received induction, while $40 \%$ of those working in statutory health settings, and $76 \%$ of those in the Department of Child, Youth and Family (CYF) received some form of induction in New Zealand social work practice.

On the other hand, commentary from the group interview participants provides considerable detail and texture regarding the quality of the induction they did receive. As highly experienced practitioners and managers, many in the key informants group had very clear professional identities and a strong sense of social work values that provided them with a lens through which to assess the quality and appropriateness of the induction they received. Generally, those who addressed the detail of their employment induction indicated that their orientation to administrative aspects of their work was satisfactory; however, the more important-and more complex and nuanced-induction required was in working with the particular forms of cultural difference at play in the New Zealand setting, specifically with regard to New Zealand's indigenous population.
TABle 4: Received induction from first New Zealand social work employer.

\begin{tabular}{lcc}
\hline & $N$ & $\%$ \\
\hline Yes & 107 & 47.3 \\
No & 119 & 52.7 \\
\hline Total & 226 & 100 \\
\hline
\end{tabular}

We had training, Treaty of Waitangi, working with Pasifika clients and this, and [they] were very limited, so how do you come about the confidence where you're not really exposed to things thatyou don't know the things that you're expected to know? (Derek, South Africa qualified, 22 years experience.)

The other thing is I went on some training and it was cultural training, it was on a marae (Marae refers to the grounds on which stand traditional Maori meeting houses. The significance of trainings being conducted on marae is that they would be subject to customary cultural protocols such as formal welcoming ceremonies (with speeches often delivered predominantly - or entirely - in the Maori language), karakia (prayers), waiata (songs) and hongi (the traditional Maori greeting involving the touching together of noses).) and the content of the training I found, as a social worker, quite disturbing and I came away from that training very confused. What seemed to be talked about and accepted was against things that I had been practising and trained and believed in and I found that very difficult and weird, what the thoughts were in that training. (Karen, UK qualified, 16 years experience.)

Oh, there was no sense that it [induction] was going to be offered, absolutely not and so I learnt an enormous amount through the job that I did and the connections that I made in the job that I did... So it wasn't part of the social work discourse in that particular-again, I won't go any wider than my experience but in that particular group, at all. It just wasn't there. (Raymond, UK qualified, 34 years experience.)

Each of these participants-and many of the others who had indicated negative initial experiences with cultural induction-stated during the group interviews that they relied on their own initiative to "fill in the gaps" they felt were missing, through building relationships with local colleagues, supervision, or seeking out other forms of training on their own. Sometimes, as with the following key informant quotes, this entailed an extensive personal investment over a period of time, as evidenced by the easy integration in the participant's speech of indigenous terminology.

What I did, living over in [East Auckland], there was a little whare [Maori "house"-likely 
TABLE 5: The extent to which overseas training helped prepare for working in New Zealand.

\begin{tabular}{|c|c|c|c|c|c|c|c|c|c|}
\hline \multirow{2}{*}{\multicolumn{2}{|c|}{$\begin{array}{l}\text { The extent to which overseas training } \\
\text { helped prepare for working in New } \\
\text { Zealand }\end{array}$}} & \multicolumn{8}{|c|}{ Grouped country of first professional qualification } \\
\hline & & UK and Ireland & Europe & $\begin{array}{c}\text { North/South } \\
\text { America }\end{array}$ & South Asia & East Asia & Oceania & Africa & Total \\
\hline \multirow{2}{*}{ Completely did not } & Count & 2 & 1 & 0 & 1 & 0 & 0 & 0 & 4 \\
\hline & Column \% & 3.3 & 3.4 & 0.0 & 7.7 & 0.0 & 0.0 & 0.0 & 14.4 \\
\hline \multirow{2}{*}{ Emphatically didn not } & Count & 2 & 1 & 1 & 1 & 0 & 0 & 0 & 5 \\
\hline & Column \% & 3.3 & 3.4 & 6.3 & 7.7 & 0.0 & 0.0 & 0.0 & 20.7 \\
\hline \multirow{2}{*}{ Did not really } & Count & 10 & 7 & 1 & 1 & 0 & 2 & 1 & 22 \\
\hline & Column \% & 16.4 & 24.1 & 6.3 & 7.7 & 0.0 & 7.4 & 3.3 & 65.2 \\
\hline \multirow{2}{*}{ Somewhat did } & Count & 17 & 4 & 4 & 5 & 0 & 6 & 7 & 43 \\
\hline & Column \% & 27.9 & 13.8 & 25.0 & 38.5 & 0.0 & 22.2 & 23.3 & 150.7 \\
\hline \multirow{2}{*}{ Emphatically did } & Count & 25 & 15 & 8 & 4 & 6 & 12 & 19 & 89 \\
\hline & Column \% & 41.0 & 51.7 & 50.0 & 30.8 & 85.7 & 44.4 & 63.3 & 367.0 \\
\hline \multirow{2}{*}{ Completely did } & Count & 5 & 1 & 2 & 1 & 1 & 7 & 3 & 20 \\
\hline & Column \% & 8.2 & 3.4 & 12.5 & 7.7 & 14.3 & 25.9 & 10.0 & 82.0 \\
\hline \multirow{2}{*}{ Total } & Count & 61 & 29 & 16 & 13 & 7 & 27 & 30 & 183 \\
\hline & Column \% & 100.0 & 100.0 & 100.0 & 100.0 & 100.0 & 100.0 & 100.0 & 100.0 \\
\hline
\end{tabular}

a community centre] over there and the kuia [female Maori elder] there taught Te Reo Maori [Maori language] and I would bring my two kids, and we would go along to this whare with other families in the area and we would learn all the waiata, all the children's kohanga [Maori language-immersion preschool] songs. I learnt all of those and could do the actions and hear the sound because to me it was really important because... coming here, thinking of New Zealand as a bicultural country or bicultural profession but I found no evidence of it at all, except you know, "don't sit on tables" was kind of the most we'd get of the Maori cultural education but not a lot else. Language, pronunciation, people didn't seem to mind how they pronounced things and I minded... and so that's why I went along to learn with my children. (Quin, South African qualified, 24 years experience.)

There's a lot of hit and miss isn't there? If you're lucky, you're going to walk into a programme and it's all laid on but if you're not, you might just have to find these things out. (Smita, India qualified, 29 years experience.)

\section{Utilisation of Skills}

Survey respondents from all countries were generally positive about the extent to which their overseas training helped to prepare them for practice in New Zealand (see Table 5). Those from East Asia, Africa, and (to a lesser extent) Europe and the Americas were more emphatically positive than those from the UK/Ireland and South Asia. Not surprisingly, more than a quarter of those whose first professional qualification was from Oceania (overwhelmingly from Australia) indicated that their qualification "completely" prepared them for practice in New Zealand.

This does not mean that participants necessarily perceived a satisfactory match between their skill sets and the requirements of the social work they did in New Zealand. The opportunity to make good use of their existing skills is regarded as very important for migrant social work professionals, who may often feel their skills are underutilised [42]. In fact, just over half of the survey respondents indicated that valuable aspects of their social work training were unable to be used in practice in New Zealand. When asked to specify, $59 \%$ of the survey participants listed a wide range of factors, mostly addressing specific clinical skills, such as specialist assessment skills, counseling, and therapybased interventions. The broad range of categories of underutilised skills is listed in Table 6 .

The issue of underutilised skills was detailed further in the key informant group interviews: there, as in the survey, participants expressed frustration primarily at the underutilisation of specific therapeutic skills.

I found it really difficult that I had all this training [in therapy with abused children] and a lot of experience which essentially I have never really used in New Zealand... I miss it because I loved that work. I found it really powerful and moving and testing. (Janet, UK qualified, 17 years experience.)

I would struggle to engage most of my current colleagues in conceptualisation [of therapeutic work]. Perhaps two out of 12 might come along with that. So yeah, there's a real challenge in terms of coming from a different theoretical background. (Raymond, UK qualified, 34 years experience.) 
TABLE 6: Valuable aspects of training underutilised in New Zealand practice $(n=172)$.

\begin{tabular}{|c|c|c|c|}
\hline & \multicolumn{2}{|c|}{ Responses } & \multirow{2}{*}{$\%$ of cases } \\
\hline & $N$ & $\%$ & \\
\hline Clinical skills & 54 & 31.4 & 52.4 \\
\hline $\begin{array}{l}\text { Working in different ways } \\
\text { (approaches) }\end{array}$ & 26 & 15.1 & 25.2 \\
\hline $\begin{array}{l}\text { Working in different ways } \\
\text { (fields/sites of practice) }\end{array}$ & 26 & 15.1 & 25.2 \\
\hline Community development skills & 13 & 7.6 & 12.6 \\
\hline Working cross-culturally & 13 & 7.6 & 12.6 \\
\hline Management skills & 6 & 3.5 & 5.8 \\
\hline Supervision skills & 6 & 3.5 & 5.8 \\
\hline Working in legal context & 6 & 3.5 & 5.8 \\
\hline Policy work & 5 & 2.9 & 4.9 \\
\hline Other & 5 & 2.9 & 4.9 \\
\hline Research skills & 4 & 2.3 & 3.9 \\
\hline Educator role & 4 & 2.3 & 3.9 \\
\hline $\begin{array}{l}\text { Working with greater autonomy } \\
\text { and decision-making }\end{array}$ & 3 & 1.7 & 2.9 \\
\hline Political advocacy & 1 & 0.6 & 1.0 \\
\hline Total & 172 & 100.0 & 167.0 \\
\hline
\end{tabular}

We were really well trained in group work-a big part of our training - and I found the social workers [here] really being scared to run groups, even if it's just educational groups or life skills or whatever, they just don't feel confident enough to do some stuff. (Alicia, South Africa trained, 24 years experience.)

When I moved to Auckland I worked in an inpatient unit where it was believed that social workers are taxi drivers... it was an absolute battle and I think most upsetting was the perception of other professionals about social work... it was only errands and when you try to do things like getting involved with groups for instance, it's just frowned upon because [Occupational Therapists] do groups. (Tanya, South Africa qualified, 30 years experience.)

7.1. Engagement with Professional Social Work Bodies. Exactly half the survey participants (147) indicated that they were members of the ANZASW, New Zealand's voluntary professional association of social workers. Almost the same number (146, or $49.7 \%)$ of the survey respondents indicated that they had been registered as social workers in an overseas jurisdiction, and nearly as many respondents $(46.6 \%)$ were registered as social workers in New Zealand. Another 14\% had applied for New Zealand registration, while more than a quarter of respondents $(26.5 \%)$ had not attempted registration. Registration of social workers is a relatively new regime in New Zealand, and not yet compulsory.
Furthermore, it is a relatively time-consuming and expensive endeavour; thus it is unsurprising that somewhat higher rates of registration were evidenced by those respondents employed in statutory agencies such as DHBs or CYF (each at $58 \%$ ), where registration is encouraged and where workers may receive reimbursement for their registration costs. On the other hand, those working outside the statutory agencies had a lower rate of registration, at $47 \%$. The costs associated with the registration process were mentioned by a number of survey participants, but one survey participant in particular articulated the impact on community agencies of supporting their workers to become registered in New Zealand.

Costs for ANZASW and SWRB are off the chart. I realise that there are economies of scale to be considered but they really are very expensive considering membership of both are essentially basic practice requirements. I am convinced that the costs cut into and undermine Agency training budgets that might otherwise support PD.

On the other hand, it appears that with time most overseas-qualified social workers do pursue professional registration in New Zealand-particularly if they had previously been registered elsewhere. More than $80 \%$ of those respondents who had held an overseas registration, and who had been resident between 10 and 20 years, had been registered by the New Zealand SWRB, whereas only a third of those overseas-registered who had been resident less than five years had been registered in New Zealand (Table 7).

Sixty percent of the survey participants had comments to make about what either the Registration Board or the Association of Social Workers could do to support border-crossing social workers and many of these comments addressed a desire that the SWRB should at least recognise, if not directly transfer, the professional registration of overseas jurisdictions.

Streamline the registration process for social workers already registered overseas.

Accept and "transfer" registration in home country if there has not been any misconduct.

Accept registration from other countries, the same as qualifications. I have been a practicing social worker for many years and I am trying to find time to do my competences, 7 years after I did them in the UK!

Accept their registration certificates as they cannot practice if they are not registered in their country (South Africa) and they come from places that are diverse and work in a multi-cultural society anyway.

They can work closer with UK SWRB to enable an easier 2-way registration process.

This last suggestion is especially pertinent, given the number of New Zealand-qualified social workers who 
TABLE 7: Overseas-registered social workers also registered with SWRB, by years resident in New Zealand.

\begin{tabular}{lcc}
\hline & $N$ & \% of cohort \\
\hline 0-4 years & 22 & 34.4 \\
5-9 years & 23 & 57.5 \\
10-19 years & 22 & 81.5 \\
$20-29$ years & 3 & 75 \\
\hline Total & 70 & \\
\hline
\end{tabular}

relocate to practice in the UK. The prospect that the registering authorities in two or more jurisdictions could pursue agreements on mutual recognition-or at least establish clear protocols to guide professionals crossing their respective borders in gaining registration-would go some considerable distance towards alleviating the frustration currently experienced by transnational social workers in New Zealand.

\section{Discussion}

In order to understand the experiences of transnational professionals, it must be recognised that the push-pull considerations weighed by individuals at the personal level are shaped in social contexts of national and international social, economic, and cultural policies. Immigration, labour market and professional body policies shape what is possible for aspiring transnationals. The qualifications, professional experience and skill-sets possessed by qualified social workers make them desirable candidates in many countries' immigration schemes, including New Zealand's, where migrants with a social work background have a facilitated pathway to permanent residency. That individual professionals are offered the opportunity to practice transnationally, or that a growing number of them take advantage of such opportunities, does not in itself make the profession transnational, however. Despite the strong discourse in the profession of a universally shared set of core social work values and practices, significant institutional hurdles continue to confront border-crossing social workers [43]. Having read the encouraging signals given by national governments that their human capital makes them highly attractive immigrants, social workers find that employers and professional bodies-including the registration authority and the professional association-appear reluctant to welcome them, or to recognise both their diverse skills and their particular needs.

One of the first professional obstacles to be encountered by transnational social workers to New Zealand involves the rigours of gaining registration, which requires the recognition of their overseas social work qualifications. Participants' experiences of difficulties in obtaining New Zealand registration, such as recognition of their overseas qualifications, are not unique. Like in New Zealand, the registration authority in the UK place the onus on the social worker to verify that their qualification is acceptable in the UK context [25]. The Social Care Workforce Research Unit found similar expressions of frustration in the UK at the expense and delays incurred by this regimen from the international social workers they studied (ibid.). Certainly this process is more difficult in New Zealand for migrants from countries whose professional education regimes are very different from the host country, or delivered in languages other than English.

However, bilateral and multilateral agreements in place to facilitate free[er] trade may have a bearing on regulatory authorities such as the SWRB. One such agreement of particular relevance for social work in New Zealand is the Trans-Tasman Mutual Recognition Arrangement (1997) [44], which provides for an arrangement between the Australian Commonwealth, State and Territory governments and the government of New Zealand. This arrangement implements mutual recognition principles relating to the sale of goods and the registration of occupations, including the principle that "a person registered to practise an occupation in Australia is entitled to practise an equivalent occupation in New Zealand, and vice versa, without the need for further testing or examination" [44]. Increasingly, mutual recognition agreements are governing the movement of workers, including social workers, in other jurisdictions. The North American Free Trade Agreement facilitates movement of social workers between the USA and Canada [24], and the European Union has similar arrangements. Given the regular exchange in the social work workforce between New Zealand, the UK, and Ireland, for example, there is no reason to suppose that mutual recognition protocols between the registration authorities could not be negotiated-perhaps subject to requirements that professionals transferring across those jurisdictions undertake appropriate induction in the local practice, legislative and policy contexts. As researchers of social work migration into Ireland have argued, "[local] communities of educators, employers and practitioners need to consider their constituents, both local populations and their diverse workforces, not alone as [local] entities, but as global and transnational phenomena" [17, page 15].

The need for greater levels of professional induction for transnational social workers is universally articulated by those studying the phenomenon in any jurisdiction $[21,23,24,42,45-50]$. That such induction is needed is beyond question: exactly what such induction should contain, or how it should be delivered, are far less clear. As with many of the above-mentioned studies, the current research has found that induction programmes coordinated by employers - including the statutory agencies in health and child welfare-were found by the migrant professionals to be not consistently offered and of highly variable quality. Thus the current employer-specific regime of induction for migrant social workers in New Zealand-especially that dealing with cultural induction, and the legislative, historical, and political contexts in which policies have been developedis inadequate for addressing the needs of the transnational workforce. However, the relevant professional bodies have yet to take the lead in this issue, and the current funding model of tertiary education in New Zealand means that siting such induction programmes in schools of social work would be an expensive option for migrant professionals-whether delivered in the context of employment or not. 
These findings can also inform the analysis of other "middling transnational" professions, especially those with strong state-dominated regulatory and delivery regimes, such as nursing and teaching. The transnational practices of these professionals-both of the overseas-qualified practicing here (wherever the here happens to be) and the locally qualified who depart to practice in other jurisdictions - have created a transnational social space that poses a continuing challenge to employers, professional bodies, and social work educators to apprehend effectively both the global knowledge and expertise they offer, and the local knowledge and expertise they need. The current study has added a New Zealand case study to the weight of international calls for the profession to respond urgently to the challenge to recognise this transnational professional space. We recommend that health and social service employers, the professional bodies, and social work educators in New Zealand engage in a comprehensive stock-take of the cultural induction practices for-and needs of-overseas-qualified social workers in the health and social services sectors. This would provide an essential baseline and a necessary step towards considering the prospect of developing a consistent, comprehensive, and systematic approach to such induction practices across sectors, institutions, and fields of practice. It is clearly time for the relevant stakeholders to individually and collectively take responsibility to codevelop the nature of the transitional professional space. Part of the solution may be to reconceptualise transnational practice as offering opportunities, not just challenges. Rather than ignoring the wide-ranging implications for migrant professionals personally and professionally, or waiting for the stakeholders to solve the dilemmas present, it is important to address policies and practices that will enable positive progress to be made. Transnational practitioners can enrich and enliven social work practice globally through a respectful and open and embedded engagement with the "local" in each node of the transnational professional space.

\section{References}

[1] N. G. Schiller, L. Basch, and C. Blanc-Szanton, "Towards a definition of transnationalism: introductory remarks and research questions," Annals of the New York Academy of Sciences, vol. 645, pp. ix-xiv, 1992.

[2] Y. N. Soysal, Limits of Citizenship: Migrants and Postnational Membership in Europe, Chicago, University of Chicago Press, Chicago, Ill, USA, 1994.

[3] E. S. Ho, "Multi-local residence, transnational networks: Chinese "Astronaut" families in New Zealand," Asian and Pacific Migration Journal, vol. 11, no. 1, pp. 145-164, 2002.

[4] A. Kobayashi, V. Preston, and A. M. Murnaghan, "Place, affect, and transnationalism through the voices of Hong Kong immigrants to Canada," Social \& Cultural Geography, vol. 12, no. 8, pp. 871-888, 2011.

[5] A. Portes, L. E. Guarnizo, and P. Landolt, "The study of transnationalism: pitfalls and promise of an emergent research field," Ethnic and Racial Studies, vol. 22, no. 2, pp. 217-237, 1999.

[6] Statistics New Zealand, "Census national highlights revised," 2006, http://www.stats.govt.nz/ /media/Statistics/Census/
2006-reports/quickstats-subject/National-Highlights/2006census-national-highlights-revised.xls.

[7] N. G. Schiller, L. Basch, and C. S. Blanc, "From immigrant to transmigrant: theorizing transnational migration," Anthropological Quarterly, vol. 68, no. 1, pp. 48-63, 1995.

[8] P. Kivisto, "Theorizing transnational immigration: a critical review of current efforts," Ethnic and Racial Studies, vol. 24, no. 4, pp. 549-577, 2001.

[9] T. Faist, "Transnationalisation in international migration: implications for the study of citizenship and culture," in Transnational Communities Programme, A. Rogers, Ed., Oxford, UK, University of Oxford, 1999.

[10] A. J. Bartley, "1.5 generation Asian migrants and intergenerational transnationalism: thoughts and challenges from New Zealand," National Identities, vol. 12, no. 4, pp. 381-395, 2010.

[11] T. Beal and F. Sos, Astronauts from Taiwan: Taiwanese Immigration to Australia and New Zealand and the Search for a New Life, Asia Pacific Research Institute \& Steele Roberts, Wellington, New Zealand, 1999.

[12] E. Ho, Y. Chen, S. Kim, and Y. Young, "In Search of a better future: report of a survey on post-school education and employment choices among Asian adolescent migrants," Tech. Rep. number 17, Population Studies Centre, University of Waikato, Hamilton, New Zealand, 1996.

[13] M. Ip, "Beyond the "settler" and "astronaut" paradigms: a new approach to the study of the new Chinese immigrants to New Zealand," Asia-Pacific Migration Research Network, pp. 13-17, 2000.

[14] E. Risler, L. A. Lowe, and L. Nackerud, "Defining social work: does the working definition work today?" Research on Social Work Practice, vol. 13, no. 3, pp. 299-309, 2003.

[15] A. U. Sale, "What is it you do again?" Community Care, no. 1774, p. 14, 2009.

[16] B. Staniforth, C. Fouché, and M. O'Brien, "Still doing what we do: defining social work in the 21st century," Journal of Social Work, vol. 11, no. 2, pp. 191-208, 2011.

[17] T. Walsh, G. Wilson, and E. O'Connor, "Local, European and global: an exploration of migration patterns of social workers into Ireland," British Journal of Social Work, vol. 40, no. 6, pp. 1978-1995, 2010.

[18] Zealand Immigration Service New, "Essential Skills in Demand Lists," 2009, http://www.immigration.govt.nz/ migrant/stream/work/skilledmigrant/LinkAdministration/ ToolboxLinks/essentialskills.htm?level=1.

[19] A. Christie and J. Campbell, "Editorial: crossing borders," Social Work Education, vol. 28, no. 6, pp. 579-582, 2009.

[20] S. Penna, I. Paylor, and J. Washington, "Globalization, social exclusion and the possibilities for global social work and welfare," European Journal of Social Work, vol. 3, no. 2, pp. 109-122, 2000.

[21] G. Simpson, "Global and local issues in the training of overseas social workers," Social Work Education, vol. 28, no. 6, pp. 655667, 2009.

[22] M. T. A. van Lanen, "Peeping at peers: a cross-national study of professionalism in social work," European Journal of Social Work, vol. 11, no. 4, pp. 469-473, 2008.

[23] P. Welbourne, G. Harrison, and D. Ford, "Social work in the UK and the global labour market: recruitment, practice and ethical considerations," International Social Work, vol. 50, no. 1, pp. 27-40, 2007.

[24] R. White, "Opportunities and challenges for social workers crossing borders," International Social Work, vol. 49, no. 5, pp. 629-640, 2006. 
[25] S. Hussein, M. Stevens, and J. Manthorpe, "International social care workers in England: profile, motivations, experiences and future expectations," Final report, Social Care Workforce Research Unit, King's College London, London, UK, 2010.

[26] L. Sklair, "Democracy and the transnational capitalist class," Annals of the American Academy of Political and Social Science, vol. 581, pp. 144-157, 2002.

[27] J. V. Beaverstock, "Re-thinking skilled international labour migration: world cities and banking organisations," Geoforum, vol. 25, no. 3, pp. 323-338, 1994.

[28] J. Salt, "Highly-skilled international migrants, careers and internal labour markets," Geoforum, vol. 19, no. 4, pp. 387399, 1988.

[29] B. Pease, "Men in social work," Affilia, vol. 26, no. 4, pp. $406-$ 418,2011

[30] E. L.-E Ho, "Migration trajectories of "highly skilled" middling transnationals: Singaporean transmigrants in London," Population, Space and Place, vol. 17, no. 1, pp. 116-129, 2011.

[31] I. Weiss-Gal and P. Welbourne, "The professionalisation of social work: a cross-national exploration," International Journal of Social Welfare, vol. 17, no. 4, pp. 281-290, 2008.

[32] K. Calderwood, K. Harper, K. Ball, and D. Liang, "When values and behaviors conflict: immigrant BSW students' experiences revealed," Journal of Ethnic and Cultural Diversity in Social Work, vol. 18, no. 1-2, pp. 110-128, 2009.

[33] L. Beddoe, C. Fouché, A. Bartley, and P. Harington, "Migrant social workers' experience in New Zealand: education and supervision issues," Social Work Education. In press.

[34] A. Bartley, L. Beddoe, J. Duke, C. Fouché, P. R. J. Harington, and R. Shah, "Crossing borders: key features of migrant social workers in New Zealand," Aotearoa New Zealand Social Work, vol. 23, no. 3, pp. 16-30, 2011.

[35] A. Bryman, "Integrating quantitative and qualitative research: how is it done?" Qualitative Research, vol. 6, no. 1, pp. 97-113, 2006.

[36] J. W. Creswell, Research Design: Qualitative, Quantitative and Mixed Methods Approaches, Sage, Los Angeles, Calif, USA, 3rd edition, 2009.

[37] B. S. A. Yeoh and S. Huang, "Introduction: fluidity and friction in talent migration," Journal of Ethnic and Migration Studies, vol. 37, no. 5, pp. 681-690, 2011.

[38] V. A. L. Colic-Peisker, "Free floating in the cosmopolis exploring the identity-belonging of transnational knowledge workers," Global Networks, vol. 10, no. 4, pp. 467-488, 2010.

[39] M. Kingma, "Nurses on the move: diversity and the work environment," Contemporary Nurse, vol. 28, no. 1-2, pp. 198206, 2008.

[40] L.-H. N. Chiang, “'Astronaut families': transnational lives of middle-class Taiwanese married women in Canada," Social and Cultural Geography, vol. 9, no. 5, pp. 505-518, 2008.

[41] S. Hussein, J. Manthorpe, and M. Stevens, "International social care workers: initial outcomes, workforce experiences and future expectations," Interim Report Phase I, Social Care Workforce Research Unit, King's College London, London, UK, 2008.

[42] J. Manthorpe, S. Hussein, N. Charles, P. Rapaport, M. Stevens, and T. Nagendran, "Social care stakeholders' perceptions of the recruitment of international practitioners in the United Kingdom-a qualitative study," European Journal of Social Work, vol. 13, no. 3, pp. 393-408, 2010.

[43] S. Hussein, M. Stevens, J. Manthorpe, and J. Moriarty, "Change and continuity: a quantitative investigation of trends and characteristics of international social workers in england," British Journal of Social Work, vol. 41, no. 6, 2011.

[44] Department of Innovation, Industry, Science and Research, "Trans-Tasman Mutual Recognition Arrangement," 2009, http://www.innovation.gov.au/Industry/TradePolicies/MRA/ Pages/Trans-TasmanMRA.aspx.

[45] S. Evans, P. Huxley, and M. Munroe, "International recruitment of social care workers and social workers: illustrations from the UK," The Hong Kong Journal of Social Work, vol. 40, no. 1-2, pp. 93-110, 2006.

[46] S. Evans, C. Baker, P. Huxley, J. White, and S. Philpin, "International recruitment of social care workers and social workers in Wales-Final Report," Tech. Rep., Swansea Centre for Social Carework Research, School of Human Sciences Swansea University, 2007.

[47] Experian, Overseas Workers in the UK Social Care, Children and Young People Sector, Skills for Care and Development, London, UK, 2007.

[48] S. Hanks and D. Sims, "Intercultural consolidation? Exploring the experiences of internationally qualified social workers and the post qualifying framework," in Proceedings of the 11th UK Joint Social Work Education Conference with the 3rd UK Social Work Research Conference, University of Hertfordshire, Hertfordshire, UK, July 2009.

[49] D. Hayes, "Increase in overseas social workers poses ethical questions for councils," Community Care, vol. 1508, pp. 1819, 2004.

[50] P. Khan and L. Dominelli, "The impact of globalization on social work in the UK," European Journal of Social Work, vol. 3, no. 2, pp. 95-108, 2000. 


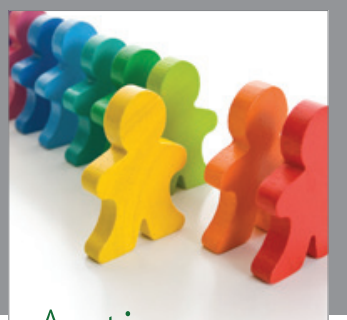

Autism

Research and Treatment
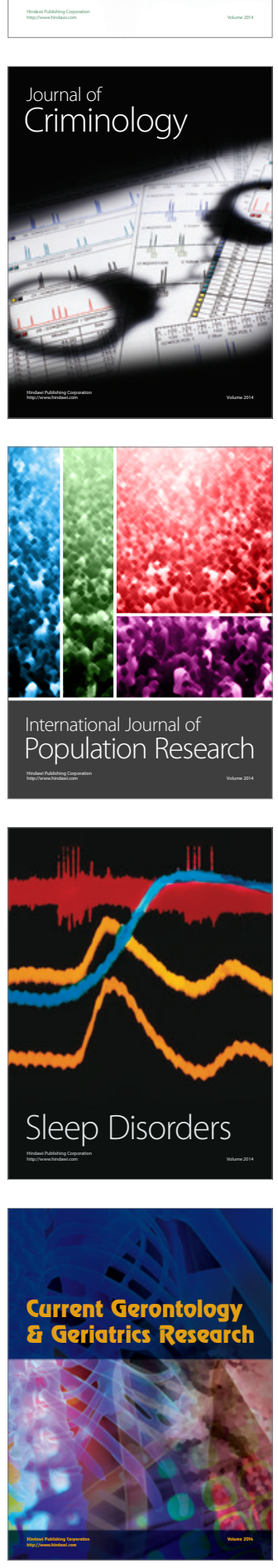
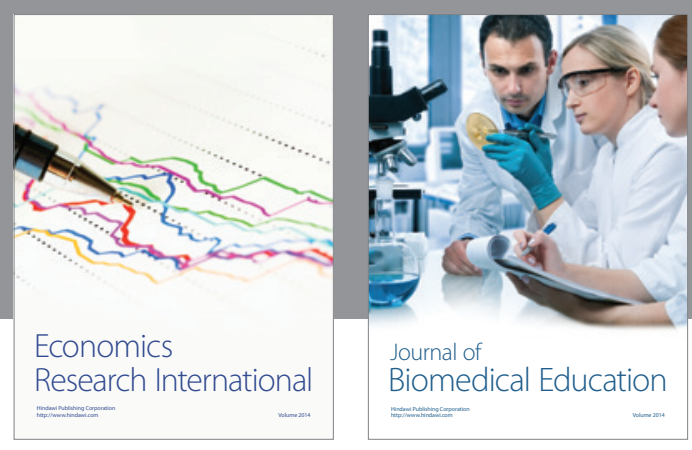

Journal of

Biomedical Education

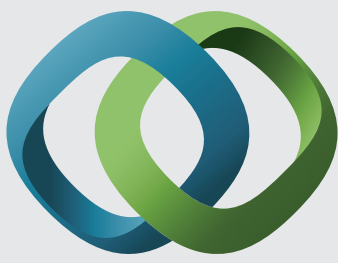

\section{Hindawi}

Submit your manuscripts at

http://www.hindawi.com
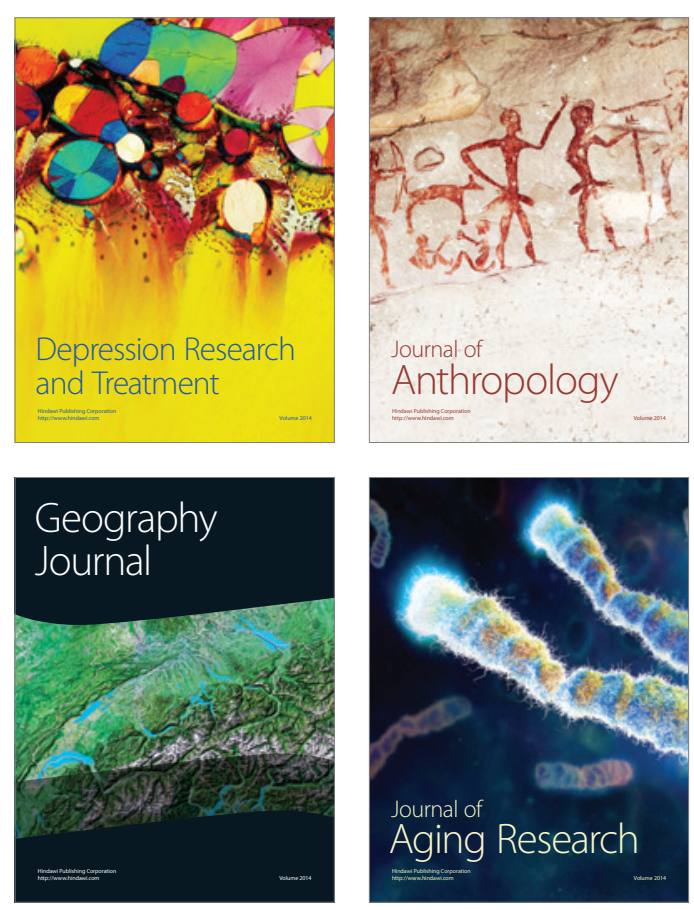

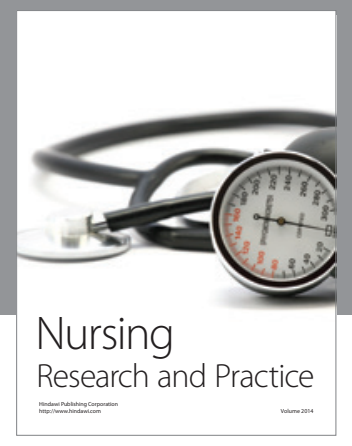

Nursing

Research and Practice

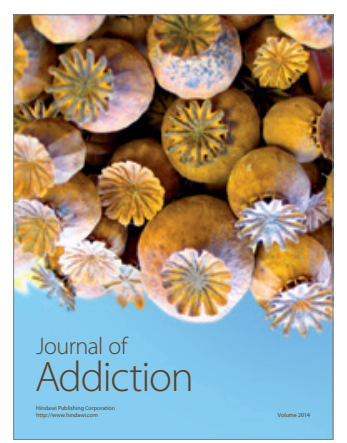

Child Development

Research

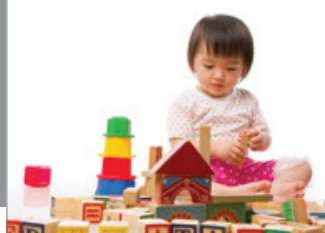

迥
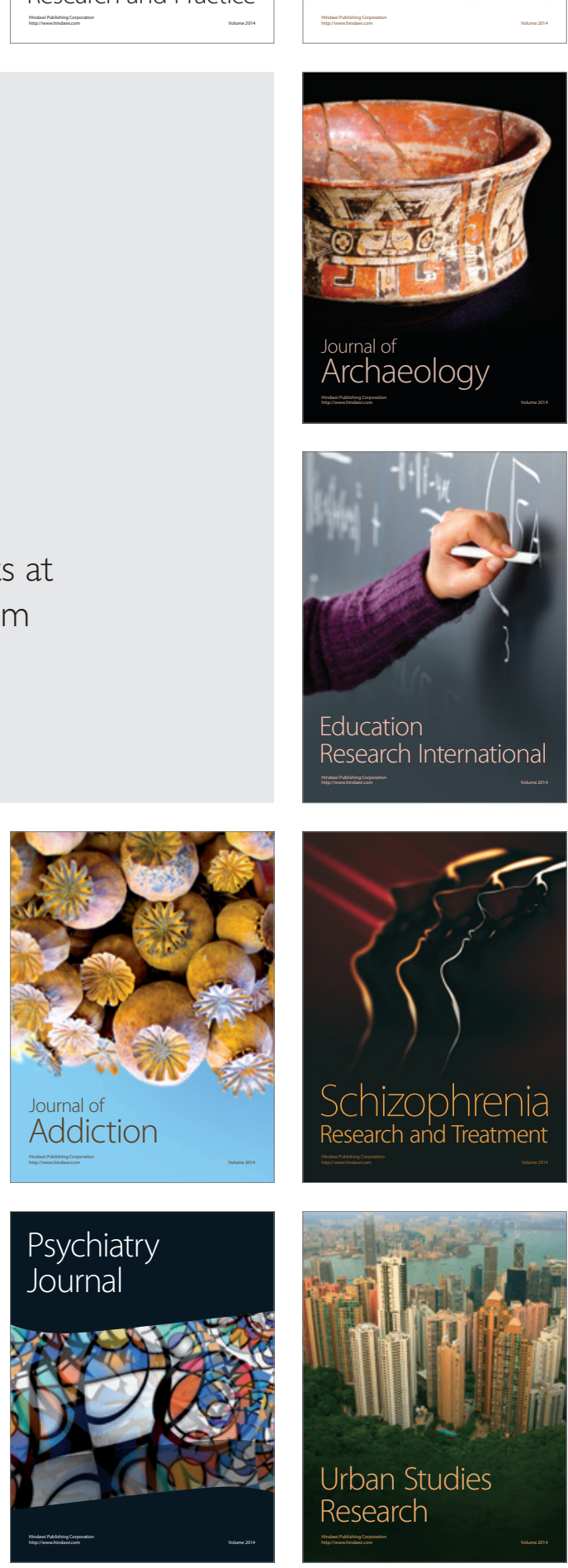